\title{
Budget Impact Analysis of an Epigenetic Test Used for Diagnosing Fetal Alcohol Spectrum Disorder from the Perspective of a Laboratory Budget Holder in Manitoba, Canada
}

\author{
Patrick Berrigan ${ }^{1} \cdot$ Geoffrey G. Hicks ${ }^{2}$ - Wendy J. Ungar ${ }^{3,4} \cdot$ Jennifer D. Zwicker ${ }^{1,5}$ (D)
}

Accepted: 6 September 2021 / Published online: 10 October 2021

(c) The Author(s) 2021

\begin{abstract}
Background and Aims Fetal alcohol spectrum disorder (FASD) is a condition that results from prenatal alcohol exposure. Though diagnosis is important for individuals with FASD to receive appropriate care, diagnosis can be difficult to obtain. Accurate diagnoses can be impeded because of an inability to confirm prenatal alcohol exposure. This is particularly problematic in instances when family cannot confirm prenatal alcohol exposure. DNA methylation testing represents a novel approach to identifying prenatal alcohol exposure via epigenetic biomarkers. The objective was to assess the impact on laboratory expenditures from adopting DNA methylation additively to the diagnostic workup for patients suspected of having FASD for whom prenatal alcohol exposure cannot be otherwise confirmed.

Methods A budget impact model was developed that incorporates laboratory cost data, population data for Manitoba Canada, literature, and expert opinion. Probabilistic analysis was conducted for the primary analysis and deterministic sensitivity analyses were conducted to assess the sensitivity of the budget impact to changes in model parameters. The perspective of the present study is that of the laboratory budget holder at a centralized laboratory in Manitoba, Canada.

Results Over a 5-year period, it was estimated that there would be 500 DNA methylation tests and the predicted budget impact to the laboratory budget holder was $\$ 207,574$ (95\% credible interval: 70,208-408,161) in Canadian dollars (CAD). Over a 10-year period, it was estimated that there would be 1017 DNA methylation tests and the predicted budget impact to the laboratory budget holder was CAD $\$ 439,470$ (95\% credible interval: 148,902-867,328).

Conclusions Findings provide insight into the impact that DNA methylation testing would have on laboratory budgets if used in the diagnostic workup for FASD in individuals for whom prenatal alcohol exposure cannot be confirmed otherwise.
\end{abstract}

\section{Introduction}

Fetal alcohol spectrum disorder (FASD) is a pattern of physical, mental, behavioral, and/or learning disabilities in individuals that results from prenatal alcohol exposure [1].

Jennifer D. Zwicker

zwicker1@ucalgary.ca

1 School of Public Policy, University of Calgary, Calgary, AB, Canada

2 Department of Biochemistry and Medical Genetics, University of Manitoba, Winnipeg, MB, Canada

3 Program of Child Health Evaluative Sciences, The Hospital for Sick Children Research Institute, Toronto, ON, Canada

4 Institute of Health Policy, Management and Evaluation, University of Toronto, Toronto, ON, Canada

5 Faculty of Kinesiology, University of Calgary, Calgary, AB, Canada
Children with FASD typically experience functional limitations in memory, attention, visual-spatial abilities, executive functioning, processing speed, intelligence, academic achievement, and language [2]. The burden of FASD is large and the average annual cost of FASD has been estimated at $\$ 21,642$ in 2006 Canadian dollars (CAD) per individual when considering direct costs (medical, education, social services, out-of-pocket costs) and indirect costs (productivity losses), with estimates varying depending on age and the severity of a patient's condition [3, 4].

Receiving a FASD diagnosis is a critical step in ensuring individuals receive appropriate interventions and care to improve outcomes [5]; however, diagnosis can be difficult to obtain [6]. Diagnosis requires a battery of tests conducted by a range of healthcare professionals and typically includes a physical examination, dysmorphology assessment, neurobehavioral assessment, and prenatal exposure to alcohol confirmation. However, accurate diagnoses can be impeded 


\section{Key Points for Decision Makers}

There is a group of children with fetal alcohol spectrum disorder (FASD) for whom a diagnosis is difficult to obtain due to an inability to confirm prenatal alcohol exposure.

The findings of the present study suggest that 500 children could benefit from DNA methylation testing over the first 5 years of this study's time horizon and 1017 children could benefit over the full 10-year time horizon if adopted in Manitoba, Canada.

Over a 5-year period, the predicted budget impact to the laboratory budget holder from introducing DNA methylation was CAD $\$ 207,574$ (95\% credible interval: $70,208-408,161)$. Over a 10 -year period, the predicted budget impact to the laboratory budget holder from introducing DNA methylation was CAD \$439,470 (95\% CI: $148,902-867,328)$.

in some children because of an inability to confirm prenatal alcohol exposure. Confirmation of prenatal alcohol exposure represents an important component of diagnosis for many children, as the presentation of FASD can resemble other conditions [7]. This is particularly problematic for adopted children and in other instances when family members are not available or unwilling to confirm prenatal alcohol exposure.

DNA methylation testing represents a novel approach to identifying prenatal alcohol exposure that does not require confirmation of exposure by family members [8]. Briefly, this technique identifies prenatal alcohol exposure through epigenetic changes that occur at the molecular level in individuals exposed to alcohol before birth [8]. As a result, DNA methylation testing could be advantageous, if used additively to the standard diagnostic workup to aid in the identification of FASD in children for whom prenatal alcohol exposure cannot be otherwise confirmed. Another advantage of DNA methylation testing is that it can be used across a wide range of ages compared with other biomarkers such as meconium or umbilical cord blood testing, which are generally only applicable at or near the time of birth due to the need to have the biological material available for testing. Consideration of the economic impact, specifically the impact on operating budgets, of DNA methylation is an important step in assessing the technology for adoption into the clinical setting.

This study evaluated implications to a laboratory budget holder of the addition of DNA methylation testing to the conventional diagnostic workup for children with suspected FASD for whom prenatal alcohol exposure cannot be otherwise confirmed. Implementing DNA methylation testing is of interest in Manitoba, Canada, so this analysis focused on the cost and resource use in this province, recognizing similar analyses could be conducted in different jurisdictions. Careful planning that takes into consideration the likely cost and resource use implications of adopting a test is important for effective budgetary planning, particularly for new genetic tests that can be more expensive than other types of tests [9]. When combined with additional information regarding the costs and benefits of the technology, findings will be of use to laboratory budget holders for budget forecasting and for decision makers assessing whether or not to adopt DNA methylation testing into the clinical setting.

\section{Methods}

\subsection{Study Design}

An economic model was constructed to estimate the budget impact for a hypothetical cohort of children at risk for FASD. A probabilistic analysis (PA) was conducted for the reference case. Deterministic one-way and scenario analyses were conducted to assess the uncertainty associated with the analysis. The reference case analysis consisted of estimates of costs to the laboratory budget holder in Manitoba, Canada and 95\% credible intervals for 5- and 10-year periods. Analysis was conducted in accordance with the recommendations of the International Society for Pharmacoeconomic Outcomes Research (ISPOR) guidelines for budget impact analysis (BIA) where applicable [10].

\subsection{Model Structure}

The study used a cohort-level condition-specific analytic model. The study modeled a scenario where DNA methylation is adopted additively to the standard diagnostic workup for patients suspected of FASD for whom prenatal alcohol exposure cannot be otherwise confirmed.

Historical birth rates and population projections from Statistics Canada were used to simulate the projected Manitoba, Canada cohort of children with FASD born between 2016/2017 and 2025/2026. To predict the number of FASD tests requiring DNA methylation, an estimate of the incidence of FASD in Manitoba was applied to the number of births occurring in each year from fiscal $2016 / 2017$ to fiscal $2025 / 2026$ and the simulated cohort of children was moved forward in time. To account for mortality, Statistics Canada Life Tables with inflated mortality to account for increased death rates in FASD were applied. An estimate for the percentage of children for whom prenatal alcohol exposure cannot be otherwise confirmed was applied to the number of children 
remaining in the cohort at age five to estimate the number of children that would receive DNA methylation testing as part of their diagnostic workup for FASD $(10 \%$, see Table 2). Five years old was chosen as the age when diagnostic testing would occur, as in many cases cognitive deficits resulting from prenatal alcohol exposure do not become apparent until after infancy and most interventions begin after 5 years of age [11]. Commencing primary school education can serve as a signalling event for the possible presence of FASD [8].

Since applying the incidence of FASD to the number of births per year would only account for positive cases, the number of children remaining in the cohort at 5 years old was inflated to reflect children who would receive testing but test negative. In addition, the model assumed that patients with FASD who test negative (false negatives) will go on to receive a second test in the following year. The cost of a DNA methylation test was applied to this group of patients. Costs were assumed to occur at the beginning of the year and mortality at the end of the year. Figure 1 provides a display of the cohort development process.

\subsection{Perspective}

The perspective of this analysis was that of a single centralized laboratory budget holder within Manitoba, Canada [12]. Given that the impact of a FASD diagnosis on healthcare utilization is not currently known, BIA on DNA methylation testing for FASD from the perspective of the broader healthcare system is not possible. From the perspective of the laboratory payer, the incremental cost associated with the addition of DNA methylation is the cost of tests alone. There are no alternative diagnostic tests likely to be displaced and it is not anticipated that laboratory costs would differ between diagnosed and undiagnosed patients with FASD.

\subsection{Patient Population}

The patient population investigated was patients in Manitoba, Canada suspected of FASD for whom prenatal alcohol exposure cannot be otherwise confirmed born between $2016 / 2017$ to fiscal 2025/2026. In the reference case, it was assumed that $100 \%$ of children for whom prenatal alcohol exposure could not be otherwise confirmed would receive
Fig. 1 Cohort development diagram. Calculations reported in Fig. 1 are deterministic and reflect the expected values using point estimates. DNA deoxyribonucleic acid, FASD fetal alcohol spectrum disorder
Between Fiscal 2016/2017 and 2025/2026 Statistics Canada predicts $n=175,162$ births in Manitoba.

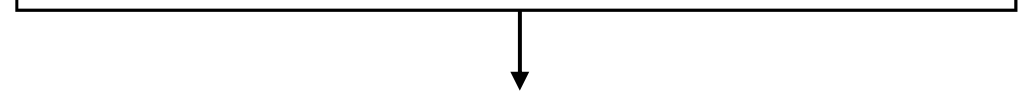

Based on an incidence of $29 / 1,000$ births $\mathbf{n}=\mathbf{5 , 0 8 0}$ children would be born with FASD.

Based on literature, $n=4,959$ children survive to age five when diagnostic testing is assumed to occur.

The estimate of 4,959 is inflated by 1.6 , as more children receive diagnostic testing than receive diagnoses. Assuming, $10 \%$ of children would receive DNA methylation testing resulting in $\mathbf{n = 7 9 3}$ primary tests between Fiscal 2020/2021 and Fiscal 2029/2030.

Based on sensitivity of DNA methylation testing, $8.3 \%$ of children receive a subsequent test resulting in $\mathbf{n}=\mathbf{8 3 0}$ total tests between Fiscal 2020/2021 and Fiscal 2029/2030. 
the test in the first year it becomes available. This assumption is tested in scenario analysis.

\subsection{Time Horizon}

The time horizon for the BIA was 10 years ranging from fiscal year 2020/2021 to fiscal year 2029/2030 for the reference case and all scenario and sensitivity analyses. For all scenarios it was assumed that DNA methylation testing is adopted into the clinical setting in fiscal year 2020/2021.

\subsection{Budget Scenarios}

The present study assessed the budget impact to the laboratory budget holder that would result from adopting DNA methylation testing additively into the diagnostic workup for patients undergoing testing for FASD for whom prenatal alcohol exposure cannot be otherwise confirmed. Budget impacts are reported annually and also aggregated over 5and 10-year periods. Credible intervals are provided for the 5- and 10-year budget impacts.

\subsection{Manitoba Birth Rates}

Historical births per year in Manitoba between fiscal 2016/2017 and 2018/2019 were taken from Statistics Canada [13]. For projected birth rates, Statistics Canada provides multiple projection scenarios that are formulated using different assumptions. A medium growth scenario was used, which was based on the following national level assumptions:

- the fertility rate reaches 1.59 children per woman in fiscal 2042/2043 and remains constant thereafter;

- Canada's life expectancy at birth reaches 87.0 years for males and 89.0 years for females in fiscal 2067/2068;

- interprovincial migration within Canada is based on the trends observed between fiscal 2003/2004 and fiscal 2008/2009;

- the immigration rate reaches $0.83 \%$ in fiscal $2042 / 2043$ and remains constant thereafter;

- the annual number of non-permanent residents reaches 1,397,060 in 2043 and remains constant thereafter; AND

- net emigration reaches $0.15 \%$ in fiscal 2042/2043 and remains constant thereafter [14].

\subsection{Incidence of Fetal Alcohol Spectrum Disorder (FASD) in Manitoba}

Though estimates of fetal alcohol syndrome (FAS) in Manitoba exist, no estimates for the incidence of FASD are known [15]. The median value from the range of values reported by Thanh et al. (2014) in Alberta, Canada was used as an approximation of the incidence of FASD in Manitoba. This corresponded to 29 cases of FASD per 1000 births [16].

\subsection{Children Requiring DNA Methylation}

Children who undergo diagnostic testing for FASD and would benefit from the addition of DNA methylation to their diagnostic workup was estimated to be $10 \%$. Clinical experts in the diagnostic process for FASD in Canada were consulted to arrive at this estimate. Given the uncertainty associated with this parameter, the implications of alternative values were assessed in sensitivity analysis.

\subsection{Negative Cases}

To account for those who undergo diagnostic testing for FASD but test negative, the present study used literaturebased estimates to inflate the number of tests that would be performed in a given year. McLachlan et al. [17] conducted a chart review to investigate resource use in a group of 70 children assessed for FASD in Alberta, Canada. Of these children, 45 received a diagnosis of FASD, nine had their diagnosis deferred, and FASD was not diagnosed in 16. A deferred diagnosis indicates that FASD could not be confirmed but the diagnostic team was unwilling to rule out the condition and future reassessment is recommended [17]. The findings of McLachlan et al. suggest that the number of children receiving testing is likely to be 1.6 times greater than the number of children who receive a diagnosis. The 1.6 was calculated by dividing the 70 patients undergoing evaluation by the 45 who received a diagnosis.

\subsection{Mortality in FASD}

Based on the findings of a systematic review [18], one study reported mortality in FASD. Burd et al. reported a standardized mortality ratio (SMR) for a cohort of children diagnosed with FASD of 3.15 [19]. This value was applied to Statistics Canada Life Tables to inflate mortality in the general public to reflect that of individuals with FASD [20] and was used to predict annual mortality in the cohort of children for each year between birth and age 5 years.

\subsection{Diagnostic Accuracy of DNA Methylation Testing}

The number of patients who would receive repeat DNA methylation testing on a subsequent occasion was informed by literature on the diagnostic accuracy of DNA methylation [8]. Specifically, a value of $91.7 \%$ for the sensitivity of DNA methylation testing was used to calculate the number of false negatives expected to occur and this number was used to approximate the number of children who would 
receive repeat testing. This corresponds to $8.3 \%$ of children receiving a second test in the following year.

\subsection{DNA Methylation Test Costing}

The cost per DNA methylation test was estimated using values from Shared Health Manitoba [21]. A bottom-up costing approach was undertaken. Cost items included were the cost of equipment, disposables associated with testing, reagents required for testing, compensation to laboratory staff, and other miscellaneous costs associated with testing. Overhead costs were not included. In total, the cost per test for DNA methylation was estimated to be $\$ 386.75$ (in 2019 CAD). Table 1 contains a list of cost items associated with DNA methylation testing. To adjust for future inflation over the study's time horizon, the Bank of Canada's target inflation rate of $2.0 \%$ per year was used [22]. Although there is a health goods and services consumer price index (CPI) in Canada, it is recommended by the Canadian Agency for Drugs and Technologies in Health, to use the general goods and services CPI. To adjust all input costs into 2019 CAD (prior to extrapolating any costs into the future), the Statistics Canada CPI for all goods and services was used [23].

\subsection{Probabilistic Analysis}

For the reference case analysis, a PA was conducted to directly incorporate uncertainty into the analysis and to estimate a 95\% credible interval for the budget impact. PA was chosen for the reference analysis based on the recommendation of the Canadian Agency for Drugs and Technologies in Health (CADTH) [24]. CADTH recommends PA for the reference case analysis in economic evaluations, as deterministic analyses will provide biased results in modeling studies. For a list of parameter values, dispersion parameters, and distributions see Table 2. For PA, each parameter estimate in the model was assigned a distribution to represent the uncertainty associated with the parameter. To parameterize distributions, dispersion parameters for beta distributions were calculated using the beta distribution variance formula. For the cost of DNA methylation testing, a value of $10 \%$ of the parameter value estimate was used. For the future inflation rate, the annual variation around the historical trend expressed as a standard deviation for the Canadian CPI between 2010 and 2019 was used [25]. For the expected number of births, the annual variation expressed as a standard deviation around the historic trend was used over the period fiscal 2010/2011 to fiscal 2018/2019 [20]. For the SMR and the percentage of children who would benefit from DNA methylation testing, 50\% of the parameter value estimate was used to reflect a higher degree of uncertainty with respect to these parameters. Of note, a lower bound of one was placed on the SMR for FASD. The justification for
Table 1 Cost items of DNA methylation on a per-test basis

\begin{tabular}{lc}
\hline Cost component & Per test (2019 CAD) \\
\hline DNA collection supplies & $\$ 24.27$ \\
DNA isolation supplies & $\$ 7.47$ \\
Disposable lab supplies & $\$ 15.01$ \\
Epic methylation array & $\$ 315.00$ \\
Miscellaneous costs & $\$ 25.00$ \\
Total & $\$ 386.75$ \\
\hline
\end{tabular}

Wages are included in the Array cost components of Table 1 and include the cost of wages, pensions, and insurance benefits

DNA deoxyribonucleic acid

${ }^{\text {a }}$ This value was an estimate meant to capture unforeseen costs associated with the testing process that would increase costs such as spills, procedural errors, and/or the breaking or expiring of laboratory supplies prior to use

applying this bound is that mortality in patients with FASD would not be less than mortality in the general public.

Values were randomly sampled from these distributions and the budget impact was calculated. This process was repeated 5000 times [24]. The $95 \%$ credible interval was calculated by taking the range of values that corresponds to the $2.5-97.5 \%$ percentiles of the 5000 budget impacts generated in PA.

\subsection{Validation}

Each calculation was checked twice by a single analyst (PB) for accuracy. Additionally, hypotheses were formed regarding the change in the model estimated budget impact from variation in model inputs. For example, if the mortality rate was increased, the model-predicted budget impact should decrease, as fewer individuals would receive diagnostic testing. These hypothesis were then tested to ensure the model predicted as expected.

\subsection{Scenario Analysis}

Due to uncertainty in parameter estimates, multiple deterministic scenario analyses were conducted. Scenario analyses were chosen in consultation with experts.

1. In the reference case, the number of children in the simulated cohort who undergo diagnostic testing for FASD was inflated by 1.6 to account for patients who would be expected to test negative. However, this value is likely to correspond to a conservative use of diagnostic resources. To assess the budget impact that would result from more liberal use of diagnostic testing, a scenario analysis was conducted that increased the multiplier from 1.6 to 2.0. 
Table 2 Parameters included in analysis

\begin{tabular}{|c|c|c|c|}
\hline Model parameter & $\begin{array}{l}\text { Parameter value estimate (dis- } \\
\text { persion parameter) }\end{array}$ & $\begin{array}{l}\text { Distribution (if } \\
\text { included in PA) }\end{array}$ & References \\
\hline \multicolumn{4}{|l|}{ Epidemiological parameters } \\
\hline FASD incidence rate in Manitoba & $29 / 1000(0.005)$ & Beta & [16] \\
\hline Multiplier accounting for patients testing negative for FASD & $1.6(0.15)$ & Beta & [17] \\
\hline Multiplier to adjust predicted births & $1.0(0.01)$ & Normal & [13] \\
\hline Mortality in FASD (SMR) & $3.15(1.6)$ & Normal & [19] \\
\hline Sensitivity of DNA metalation testing & $91.7 \%(5.5 \%)$ & Beta & [8] \\
\hline$\%$ of children who benefit from DNA methylation & $10 \%$ (range: $5-20$ ) & Uniform & Expert opinion \\
\hline \multicolumn{4}{|l|}{ Cost parameters } \\
\hline Inflation rate & $1.02(0.005)$ & Normal & [25] \\
\hline Cost of DNA methylation & $\mathrm{CAD} \$ 387(38.7)$ & Gamma & {$[21]$} \\
\hline \multicolumn{4}{|l|}{ Historical and projected births in Manitoba } \\
\hline \multicolumn{4}{|l|}{ Historical births in Manitoba } \\
\hline $2011 / 2012^{\mathrm{a}}$ & 15,983 & NA & [13] \\
\hline $2012 / 2013^{\mathrm{a}}$ & 16,488 & NA & [13] \\
\hline $2013 / 2014^{\mathrm{a}}$ & 16,334 & NA & [13] \\
\hline $2014 / 2015^{\mathrm{a}}$ & 16703 & NA & [13] \\
\hline $2015 / 2016^{\mathrm{a}}$ & 16747 & NA & [13] \\
\hline $2016 / 2017$ & 16,967 & NA & [13] \\
\hline $2017 / 2018$ & 17,218 & NA & [13] \\
\hline $2018 / 2019$ & 17,477 & NA & [13] \\
\hline \multicolumn{4}{|l|}{ Projected future births in Manitoba ${ }^{b}$} \\
\hline $2019 / 2020$ & 17,400 & NA & [14] \\
\hline $2020 / 2021$ & 17,500 & NA & {$[14]$} \\
\hline $2021 / 2022$ & 17,600 & NA & [14] \\
\hline $2022 / 2023$ & 17,700 & NA & [14] \\
\hline $2023 / 2024$ & 17,700 & NA & {$[14]$} \\
\hline $2024 / 2025$ & 17,800 & NA & [14] \\
\hline $2025 / 2026$ & 17,800 & NA & {$[14]$} \\
\hline
\end{tabular}

$C A D$ Canadian dollars, $D N A$ deoxyribonucleic acid, $F A S D$ fetal alcohol spectrum disorder, $P A$ probability analysis, $S A$ sensitivity analysis, $S M R$ standardized mortality ratio

${ }^{\mathrm{a}}$ The corresponding value was used for a deterministic scenario analysis but not for the reference case analysis

${ }^{\mathrm{b}}$ The parameters for projected future births were not varied independently in probabilistic analysis but instead were varied based on a single multiplier. For example, if this multiplier was set to 1.05 than the number of projected births in each year would be increased by 1.05

2. The reference case assumed that the incidence of FASD in Manitoba is 29 per 1000 births. A scenario analysis was conducted assuming that this value is equal to the upper bound reported by Thanh et al. [16] for the incidence of FASD in Alberta, Canada. This corresponds to an incidence rate of 43.8 per 1000 births.

3. In the reference case analysis, it was assumed that all children who would benefit from DNA methylation testing receive it as soon as the technology becomes available. However, in a scenario analysis it was assumed that after becoming available in 2020/2021, the use of DNA methylation testing would start at $25 \%$ and increase by $25 \%$ each year until reaching $100 \%$ in 4 years.

4. In the reference case analysis, it was assumed that diagnostic testing occurs at 5 years of age. In a scenario analysis, it was assumed that diagnostic testing occurs at 10 years of age. The older age would translate to more fatalities occurring prior to individuals receiving diagnostic testing and subsequently fewer diagnostic tests compared with the reference case scenario. Age 10 years was also used as an alternative age at which children would receive diagnostic testing in a scenario analysis in a previous economic evaluation of FASD screening [26].

\subsection{One-Way Sensitivity Analysis}

For deterministic one-way sensitivity analysis, uncertain parameter values were varied one at a time over intervals provided by subject matter experts or taken from literature 
Table 3 One-way sensitivity analysis ranges

\begin{tabular}{|c|c|c|}
\hline Parameter & Range & Rationale for interval \\
\hline (1) Cost of DNA methylation testing & $\$ 330-\$ 1500 \mathrm{CAD}$ & $\begin{array}{l}\text { The lower bound is the cost of a methylation array alone } \\
\text { and the upper bound is the cost of a genetic test if } \\
\text { conducted at a private lab in Manitoba }{ }^{b}\end{array}$ \\
\hline (2) FASD incidence rate in Manitoba & $14.2-43.8$ per 1000 births & Range of values reported in Thanh et al. [16] \\
\hline $\begin{array}{l}\text { (3) Multiplier accounting for patients testing negative for } \\
\text { FASD }\end{array}$ & $1.6-1.9$ & 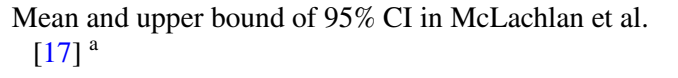 \\
\hline (4) Mortality in FASD & $1.00-6.29$ & $\begin{array}{l}\text { Lower bound is mortality in general public and upper } \\
\text { bound reflects SMR for FAS in Burd et al. [19] }\end{array}$ \\
\hline (5) Multiplier to adjust predicted births & $0.97-1.03$ & $\begin{array}{l}\text { Range of projected birth rates reported by Statistics } \\
\text { Canada for fiscal 2018/2019 [14] }\end{array}$ \\
\hline (6) Inflation rate & $0.90-2.90 \%$ & Range of CPI in Canada between 2010 and 2019 [25] \\
\hline (7) Sensitivity of DNA methylation testing & $78.1-98.9 \%$ & $95 \%$ CI reported in Lussier et al. $[8]^{\mathrm{a}}$ \\
\hline $\begin{array}{l}\text { (8) Percentage of children who benefit from DNA meth- } \\
\text { ylation }\end{array}$ & $5-20 \%$ & Expert opinion \\
\hline
\end{tabular}

$C I$ confidence interval, $C P I$ consumer price index, DNA deoxyribonucleic acid, FAS fetal alcohol syndrome, FASD fetal alcohol spectrum disorder, $S M R$ standardized mortality ratio

${ }^{\mathrm{a}} 95 \%$ confidence intervals were calculated assuming a beta distribution for the corresponding parameter

${ }^{\mathrm{b}}$ This information was obtained through personal communication with Shared Health Manitoba

representing the plausible range of values for the corresponding parameter (see Table 3). The resulting budget impacts are presented in a tornado diagram.

\section{Results}

\subsection{Reference Case}

Table 4 shows the predicted budget impact if DNA methylation testing were used for each of the 10 years between fiscal 2020/2021 and 2029/2030 in the diagnostic workup in children for which prenatal alcohol exposure cannot be otherwise confirmed. In the present study, all cost estimates reflect the year for which they are reported and were not adjusted to a common year prior to reporting. Costs reported for an interval (i.e. 5-years or 10-years) reflect the estimated total number of units of currency the budget holder would be required to spend over the interval. Over a 5-year period it was estimated that there would be 500 DNA methylation tests and the predicted budget impact to the laboratory budget holder was CAD $\$ 207,574$ (95\% credible interval $70,208-408,161)$. Over a 10 -year period, it was estimated that there would be 1017 DNA methylation tests and the predicted budget impact to the laboratory budget holder was CAD $\$ 439,470$ (95\% credible interval 148,902-867,328).

\subsection{Deterministic Scenario Analyses}

When evaluated at the point parameter value estimates presented in Table 2, the model predicts 408 DNA methylation tests and a budget impact of CAD $\$ 169,539$ over 5 years and 830 DNA methylation tests and a budget impact of CAD $\$ 359,087$ over 10 years. If the multiplier used to account for patients who would test negative is increased from 1.6 to 2.0, over 5 years it was estimated that there would be 506 tests and a budget impact of CAD $\$ 209,794$. Over 10 years, it was estimated that there would be 1029 tests and a budget impact of CAD $\$ 444,827$ (see Table 5A). If the incidence of FASD in Manitoba was 43.8 per 1000 births, over 5 years it was estimated that there would be 617 tests and a budget impact of CAD\$256,062. Over 10

Table 4 Budget impact of DNA methylation testing: reference case

\begin{tabular}{lll}
\hline Fiscal year & $\begin{array}{l}\text { DNA meth- } \\
\text { ylation tests }\end{array}$ & Budget impact (95\% credible interval) \\
\hline $2020 / 2021$ & 94 & $\$ 39,091$ \\
$2021 / 2022$ & 100 & $\$ 40,456$ \\
$2022 / 2023$ & 102 & $\$ 41,879$ \\
$2023 / 2024$ & 102 & $\$ 42,526$ \\
$2024 / 2025$ & 102 & $\$ 43,621$ \\
5 -year total & 500 & $\$ 207,574(\$ 70,208-\$ 408,161)$ \\
$2025 / 2026$ & 103 & $\$ 44,744$ \\
$2026 / 2027$ & 103 & $\$ 45,896$ \\
$2027 / 2028$ & 103 & $\$ 46,812$ \\
$2028 / 2029$ & 104 & $\$ 48,018$ \\
$2029 / 2030$ & 104 & $\$ 46,425$ \\
10 -year total & 1017 & $\$ 439,470(\$ 148,902-\$ 867,328)$ \\
\hline
\end{tabular}

$D N A$ deoxyribonucleic acid, FASD fetal alcohol spectrum disorder 
years, it was estimated that there would be 1254 tests and a budget impact of CAD $\$ 542,346$ (see Table 5B). In the reference case analysis, it was assumed that $100 \%$ of patients who would benefit from DNA methylation receive it in the year the test becomes available. However, if after becoming available in 2020/2021 its use increased by $25 \%$ each year until reaching $100 \%$ in 4 years, over 5 years it was estimated that there would be 288 tests and a budget impact of CAD\$122,991. Over 10 years, it was estimated that there would be 710 tests and a budget impact of CAD $\$ 312,538$ (see Table 5C). If, instead of occurring at age 5 years, diagnostic testing occurred at age 10 years, over 5 years it was estimated that there would be 387 tests and a budget impact of CAD $\$ 160,857$. Over 10 years, it was estimated there would be 799 tests and a budget impact of CAD $\$ 345,755$ (see Table 5D). Table 5 shows the predicted budget impact and number of tests for each scenario analysis for each year between fiscal 2020/2021 and 2029/2030.

\subsection{Deterministic One-Way Sensitivity Analysis}

The parameter representing the cost of DNA methylation testing had the most impact in both the 5- and 10-year scenarios. This was followed by the percentage of children for whom prenatal alcohol exposure cannot be otherwise confirmed; FASD incidence in Manitoba; and the projected future inflation rate. The multiplier accounting for patients who would test negative for FASD; the sensitivity of DNA methylation testing to FASD; the multiplier for projected birth rates; and FASD mortality had comparatively lower budget impacts. Figure 2 is a tornado diagram demonstrating the relative impact of uncertain parameters on the budget in the 5- and 10-year scenarios.

\section{Discussion}

The present study assessed the budget impact to the laboratory budget holder that would result from adopting DNA methylation testing additively into the diagnostic workup for patients undergoing testing for FASD for whom prenatal alcohol exposure cannot be otherwise confirmed. At present, we are aware of no other published BIA assessing diagnostic tools for patients suspected of FASD. Given the paucity of modeling studies related to this topic, the present study will contribute to the literature.

The findings of the present study suggests that 500 children could benefit from DNA methylation testing over the first 5 years of this study's time horizon and 1017 children could benefit over the full 10-year time horizon. Children could benefit by either receiving a FASD diagnosis or by ruling out FASD so that other diagnostic investigations can be prioritized. Research suggests that a FASD diagnosis can potentially lead to children receiving more appropriate care, and appropriate FASD care can have substantial positive impacts for a person and their family members. A modeling study by Hopkins et al. estimated that a patient receiving specialized FASD care could expect to earn an additional $\$ 32,133$ (2019 CAD) per year in income compared with someone not receiving this care [27]. Providing children

Table 5 Scenario analysis

\begin{tabular}{|c|c|c|c|c|c|c|c|c|}
\hline \multirow[t]{2}{*}{ Fiscal year } & \multicolumn{2}{|c|}{$\begin{array}{l}\text { (A) DNA methylation testing: } \\
\text { more liberal use of diagnostic } \\
\text { testing }\end{array}$} & \multicolumn{2}{|c|}{$\begin{array}{l}\text { (B) DNA methylation testing: } \\
\text { inflated FASD incidence rate }\end{array}$} & \multicolumn{2}{|c|}{$\begin{array}{l}\text { (C) DNA methylation testing: } \\
\text { gradual uptake of } 25 \% \text { per } \\
\text { year }\end{array}$} & \multicolumn{2}{|c|}{$\begin{array}{l}\text { (D) DNA methylation testing: } \\
\text { testing at } 10 \text { years of age }\end{array}$} \\
\hline & $\begin{array}{l}\text { DNA meth- } \\
\text { ylation tests }\end{array}$ & Budget impact & $\begin{array}{l}\text { DNA meth- } \\
\text { ylation tests }\end{array}$ & Budget impact & $\begin{array}{l}\text { DNA meth- } \\
\text { ylation tests }\end{array}$ & Budget impact & $\begin{array}{l}\text { DNA meth- } \\
\text { ylation tests }\end{array}$ & Budget impact \\
\hline $2020 / 2021$ & 96 & $\$ 39,498$ & 116 & $\$ 48,209$ & 19 & $\$ 9182$ & 72 & $\$ 30,018$ \\
\hline $2021 / 2022$ & 101 & $\$ 40,884$ & 124 & $\$ 49,901$ & 41 & $\$ 17,350$ & 78 & $\$ 31,586$ \\
\hline $2022 / 2023$ & 103 & $\$ 42,329$ & 126 & $\$ 51,664$ & 62 & $\$ 26,085$ & 78 & $\$ 31,917$ \\
\hline $2023 / 2024$ & 103 & $\$ 42,986$ & 125 & $\$ 52,466$ & 83 & $\$ 34,738$ & 79 & $\$ 33,290$ \\
\hline $2024 / 2025$ & 103 & $\$ 44,097$ & 126 & $\$ 53,822$ & 83 & $\$ 35,636$ & 80 & $\$ 34,046$ \\
\hline 5-year total & 506 & $\$ 209,794$ & 617 & $\$ 256,062$ & 288 & $\$ 122,991$ & 387 & $\$ 160,857$ \\
\hline $2025 / 2026$ & 104 & $\$ 45,236$ & 127 & $\$ 55,213$ & 84 & $\$ 36,556$ & 81 & $\$ 35,183$ \\
\hline $2026 / 2027$ & 104 & $\$ 46,403$ & 127 & $\$ 56,637$ & 84 & $\$ 37,499$ & 82 & $\$ 36,417$ \\
\hline $2027 / 2028$ & 104 & $\$ 47,331$ & 127 & $\$ 57,770$ & 84 & $\$ 38,249$ & 83 & $\$ 37,704$ \\
\hline 2028/2029 & 105 & $\$ 48,551$ & 128 & $\$ 59,258$ & 85 & $\$ 39,235$ & 83 & $\$ 38,289$ \\
\hline $2029 / 2030$ & 105 & $\$ 47,511$ & 128 & $\$ 57,407$ & 85 & $\$ 38,009$ & 83 & $\$ 37,306$ \\
\hline 10 -year total & 1029 & $\$ 444,827$ & 1254 & $\$ 542,346$ & 710 & $\$ 312,538$ & 799 & $\$ 345,755$ \\
\hline
\end{tabular}

$D N A$ deoxyribonucleic acid, FASD fetal alcohol spectrum disorder 


\section{A 5-year Time-Horizon}

Cost of DNA Methylation Testing (\$330 - \$1,500)

$\%$ of Children who Benefit from DNA Methylation (5\%-20\%)

FASD Incidence in Manitoba (14.2-43.8 per 1,000 births)

Inflation Rate (0.90\%-2.90\%)

Multiplier for Patients who Test Negative (1.6-1.9)

Sensitivity of DNA Methylation Testing (78.1\%-98.9\%)

FASD Mortality (SMR: 1.00-6.29)

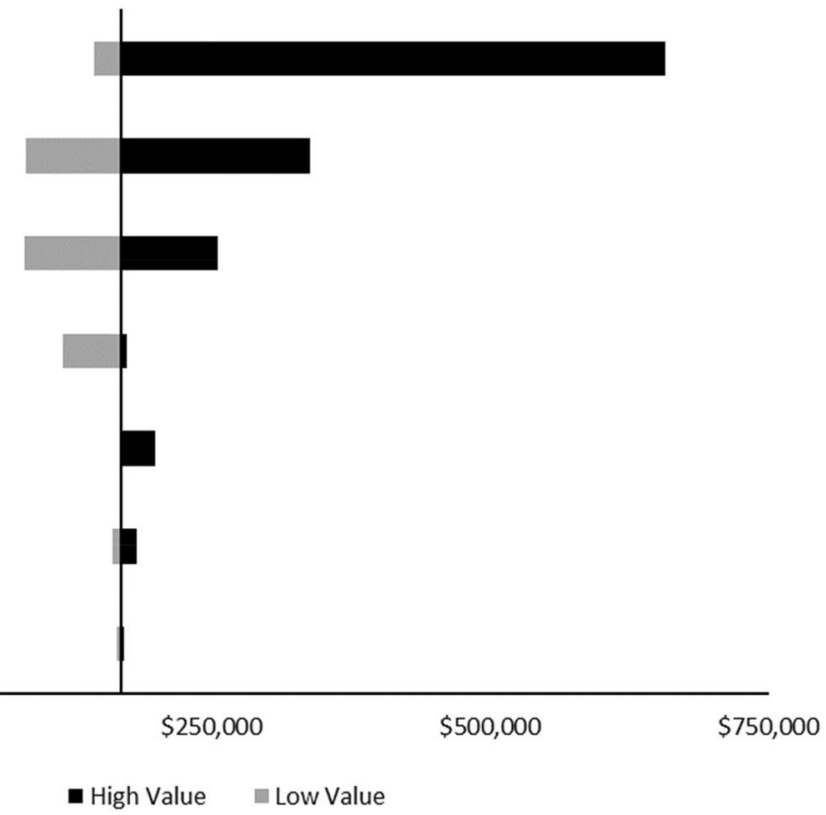

\section{B 10-year Time Horizon}

Cost of DNA Methylation Testing (\$330 - \$1,500)

$\%$ of Children who Benefit from DNA Methylation (5\%-20\%)

FASD Incidence in Manitoba (14.2-43.8 per 1,000 births)

Inflation Rate (0.90\%-2.90\%)

Multiplier for Patients who Test Negative (1.6-1.9)

Sensitivity of DNA Methylation Testing (78.1\%-98.9\%)

Multiplier for Projected Births (0.97-1.03)

FASD Mortality (SMR: 1.00-6.29)

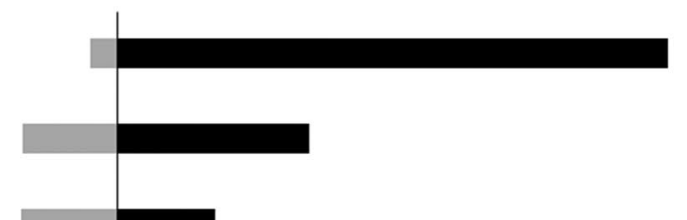

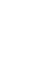


patients at risk or suspected of being at risk for a given disease or condition. An important consideration regarding the use of DNA methylation testing in this capacity is that there exist other screening tools for FASD that may potentially be more cost effective [26]. As a result, cost-effectiveness analysis (CEA) would be required to determine if DNA methylation testing would be an efficient use of resources compared with the comparatively lower cost screening tools currently available [29]. As a result, a CEA investigating the use of DNA methylation as a screening tool would represent an area where additional research on this topic would be valuable. Additionally, the impact of a FASD diagnosis on healthcare resource use and patients' quality of life is currently unknown. An understanding of how quality of life and resource use would change following a FASD diagnosis would represent an important contribution to the literature.

The present study is subject to several limitations. The first limitation is that this study relied on expert opinion for some model components due to a lack of published literature. The large degree of uncertainty associated with some of the parameter values resulted in large credible intervals for the budget impacts presented. Furthermore, it was assumed that DNA methylation would not increase the number of tests being conducted each year but instead increase the diagnostic accuracy of tests in a select group of patients. However, it is possible that if physicians had access to a test that did not require confirmation from families to identify prenatal alcohol exposure, they may send more children for FASD diagnostic testing, as the diagnostic process would be less likely hampered by an inability to confirm prenatal alcohol exposure. If the adoption of DNA methylation results in more tests being conducted, due to the ability to identify prenatal alcohol exposure in more children, the budget impact reported in this study will be underestimated.

Furthermore, this study limited its analysis to the perspective of the laboratory payer. As a result, the findings of the present study are not able to fully justify the adoption or rejection of DNA methylation for the target patient group from other system perspectives. Consequently, additional research on the value for money of this technology will be required. This study assumed that the cost of DNA methylation will be borne completely by the laboratory budget holder. However, it is possible that all or a portion of the test will be funded by patients out of pocket or their insurers. Finally, it was anticipated that DNA methylation would be adopted in a single centralized location with a single budget holder. Should it be the case that DNA methylation is not funded in this manner and costs are divided between several laboratory budget holders distributed throughout the province, cost estimates may be inaccurate.

\section{Conclusion}

To date, there have been few modeling studies in FASD and the present study represents the first BIA assessing an epigenetic test for FASD [26, 27, 30]. Findings of the present study will be of use to laboratory budget holders in jurisdictions with a similar population to Manitoba, Canada for budget forecasting and when combined with additional evidence on other costs and benefits associated with the technology for decision makers assessing whether or not to adopt DNA methylation testing into the clinical setting.

Acknowledgements We gratefully acknowledge the contributions from Kids Brain Health Network funded through The Networks of Centers of Excellence Program. Authors gratefully acknowledge the clinical expertise and expert advice of Dr. Gail Andrew.

\section{Declarations}

Funding We gratefully acknowledge the contributions from Kids Brain Health Network funded through The Networks of Centers of Excellence Program. Wendy J. Ungar is supported by a Tier 1 Canada Research Chair in Economic Evaluation and Technology Assessment in Child Health. Jennifer D. Zwicker is supported by a Tier II Canada Research Chair in Disability Policy for Children and Youth.

Conflict of interest The authors are aware of no conflicts of interest concerning this publication.

Ethics approval Ethical approval is not required for simulation-based studies in the present study's jurisdiction.

Consent to participate Not relevant to this study.

Consent for publication Not relevant to this study.

Availability of data and material All data used to construct this model from both primary and secondary sources has been presented within this manuscript.

Code availability To obtain a copy of the model, please contact the corresponding author JZ.

Author contributions All authors contributed to the planning, development and conduct of this study. Conceptualization was formed by JZ and PB. Analysis was performed by PB and reviewed by all authors. The first draft of the manuscript was written by PB and all authors commented on versions of the manuscript. All authors read and approved the final manuscript.

Open Access This article is licensed under a Creative Commons Attribution-NonCommercial 4.0 International License, which permits any non-commercial use, sharing, adaptation, distribution and reproduction in any medium or format, as long as you give appropriate credit to the original author(s) and the source, provide a link to the Creative Commons licence, and indicate if changes were made. The images or other third party material in this article are included in the article's Creative 
Commons licence, unless indicated otherwise in a credit line to the material. If material is not included in the article's Creative Commons licence and your intended use is not permitted by statutory regulation or exceeds the permitted use, you will need to obtain permission directly from the copyright holder. To view a copy of this licence, visit http://creativecommons.org/licenses/by-nc/4.0/.

\section{References}

1. Chudley AE, Conry J, Cook JL, et al. Fetal alcohol spectrum disorder: Canadian guidelines for diagnosis. CMAJ. 2005;172:S121. https://doi.org/10.1503/cmaj.1040302.

2. Mattson SN, Crocker N, Nguyen TT. Fetal alcohol spectrum disorders: neuropsychological and behavioral features. Neuropsychol Rev. 2011;21:81-101. https://doi.org/10.1007/ s11065-011-9167-9.

3. Stade B, Alaa A, Bennett D, et al. The burden of prenatal exposure to alcohol: revised measurement of cost. J Popul Ther Clin Pharmacol. Burd Prenat Expo to Alcohol Revised Meas COST 2009, vol. 16, p. e91-102. https://jptcp.com/index.php/jptcp/artic le/view/569. Accessed 2 Feb 2021.

4. Stade B, Ungar WJ, Stevens BJ, et al. The burden of prenatal exposure to alcohol: measurement of cost. JFAS Int. 2006. https:// doi.org/10.1093/pch/9.suppl_a.41aa (Published Online First).

5. Jirikowic T, Gelo J, Astley S. Children and youth with fetal alcohol spectrum disorders: summary of intervention recommendations after clinical diagnosis. Intellect Dev Disabil. 2010;48:330 44. https://doi.org/10.1352/1934-9556-48.5.330.

6. Benz J, Rasmussen C, Andrew G. Diagnosing fetal alcohol spectrum disorder: history, challenges and future directions. Paediatr Child Health. 2009;14:231-7. https://doi.org/10.1093/pch/14.4. 231.

7. Cook JL, Green CR, Lilley CM, et al. Fetal alcohol spectrum disorder: a guideline for diagnosis across the lifespan. CMAJ. 2016;188:191-7. https://doi.org/10.1503/cmaj.141593.

8. Lussier AA, Morin AM, MacIsaac JL, et al. DNA methylation as a predictor of fetal alcohol spectrum disorder. Clin Epigenet. 2018;10:5. https://doi.org/10.1186/s13148-018-0439-6.

9. Phillips K, Ramsey SD, Sakowski J. Genetic testing and pharmacogenomics: Issues for determining the impact to healthcare delivery and costs. Am J Manag Care. 2004;10:425-33. https:// www.researchgate.net/publication/8413508. Accessed 2 Feb 2021.

10. Sullivan SD, Mauskopf JA, Augustovski F, et al. Budget impact analysis-principles of good practice: report of the ISPOR 2012 Budget Impact Analysis Good Practice II Task Force introduction definition and intended use. Value Health. 2013;17:5-14. https:// doi.org/10.1016/j.jval.2013.08.2291.

11. Petrenko CLM, Alto ME. Interventions in fetal alcohol spectrum disorders: an international perspective. Eur J Med Genet. 2017;60:79-91. https://doi.org/10.1016/j.ejmg.2016.10.005.

12. Canadian Agency for Drugs and Technologies in Health (CADTH). Funding of laboratory testing in Canada. CADTH Environ Scan. 2011:1-5. https://www.cadth.ca/media/pdf/Fundi ng_Laboratory_Testing_Canada_es-19_e.pdf. Accessed 9 Jan 2021.

13. Statistics Canada. Estimates of the components of demographic growth, annual. 2020. https://www150.statcan.gc.ca/t1/tbl1/en/tv. action?pid=1710000801. Accessed 5 July 2020.

14. Statistics Canada. Components of projected population growth, by projection scenario. 2020. https://www150.statcan.gc.ca/t1/tbl1/ en/tv.action?pid=1710005801. Accessed 5 July 2020.
15. Williams RJ, Odaibo FS, McGee JM. Incidence of fetal alcohol syndrome in northeastern Manitoba. Can J Public Health. 1999;90:192-4. https://doi.org/10.1007/bf03404505.

16. Thanh NX, Jonsson E, Salmon A, et al. View of incidence and prevelance of fetal alcohol spectrum disorder by sex and age group in Alberta, Canada. J Popul Ther Clin Pharmacol 2014:e395-404. https://jptcp.com/index.php/jptcp/article/view/316/263. Accessed 17 Aug 2020.

17. McLachlan K, Andrew G, Pei J, et al. View of assessing FASD in young children: exploring clinical complexities and diagnostic challenges. J Popul Ther Clin Pharmacol 2015;22:e108-24. https://www.jptcp.com/index.php/jptcp/article/view/280/232. Accessed 20 June 2020.

18. Popova S, Lange S, Shield K, et al. Comorbidity of fetal alcohol spectrum disorder: a systematic review and meta-analysis. Lancet. 2016;387:978-87. https://doi.org/10.1016/S0140-6736(15) 01345-8.

19. Burd L, Klug MG, Bueling R, et al. Mortality rates in subjects with fetal alcohol spectrum disorders and their siblings. Birth Defects Res Part A Clin Mol Teratol. 2008;82:217-23. https:// doi.org/10.1002/bdra.20445.

20. Statistics Canada. Table 13-10-0114-01: life expectancy and other elements of the life table, Canada, all provinces except Prince Edward Island. 2020. https://doi.org/10.25318/1310011401-eng

21. Government of Manitoba. Shared Health Manitoba-Homepage. https://sharedhealthmb.ca/. Accessed 21 June 2021.

22. Bank of Canada. Inflation. 2020. https://www.bankofcanada.ca/ core-functions/monetary-policy/inflation/. Accessed 3 July 2020.

23. Bank of Canada. Inflation calculator. 2020. https://www.banko fcanada.ca/rates/related/inflation-calculator/. Accessed 3 July 2020.

24. Canadian Agency for Drugs and Technologies in Health. Guidelines for the economic evaluation of health technologies: Canada 4th edition CADTH methods and guidelines service line: CADTH methods and guidelines. 2017.

25. Statistics Canada. Consumer Price Index. 2020. https://www150. statcan.gc.ca/t1/tbl1/en/tv.action?pid=1810000413. Accessed 7 Feb 2020.

26. Berrigan P, Andrew G, Reynolds JN, et al. The cost-effectiveness of screening tools used in the diagnosis of fetal alcohol spectrum disorder: a modelled analysis. BMC Public Health. 2019;19:1-12. https://doi.org/10.1186/s12889-019-8110-5.

27. Hopkins RB, Paradis J, Roshankar T, et al. Universal or targeted screening for fetal alcohol exposure: a cost-effectiveness analysis. J Stud Alcohol Drugs. 2008;69:510-9. https://doi.org/10.15288/ jsad.2008.69.510.

28. Berrigan P, Scott CWM, Zwicker JD. Employment, education, and income for Canadians with developmental disability: analysis from the 2017 Canadian survey on disability. J Autism Dev Disord. 2020. https://doi.org/10.1007/s10803-020-04603-3.

29. Children's Healthcare Canada. National screening tool kit for children and youth identified and potentially affected by FASD. 2019. https://ken.childrenshealthcarecanada.ca/xwiki/bin/view/FASDS creeningToolkit/National+Screening+Tool+Kit+for+Children+ and+Youth+Identified+and+Potentially+Affected+by+FASD Accessed 9 July 2020.

30. Thanh XN, Jonsson E, Moffatt J, et al. An economic evaluation of the parent-child assistance program for preventing fetal alcohol spectrum disorder in Alberta, Canada. Adm Policy Ment Health. 2015;42:10-5. https://doi.org/10.1007/s10488-014-0537-5. 